\section{Doxylamine Allergy in a Pregnant Woman: Suitability of the Basophil Activation Test}

Rial MJ ${ }^{1,3}$, Fernández-Nieto $\mathrm{M}^{1,3}$, Rodrigo-Muñoz $\mathrm{JM}^{2}$, Sastre $\mathrm{B}^{2,3}$, Sastre $\mathrm{J}^{1,3}$, del Pozo $\mathrm{V}^{2,3}$

${ }^{1}$ Allergy Department, Hospital Universitario Fundación Jiménez Díaz, Madrid, Spain

${ }^{2}$ Immunology Department, Instituto de Investigación Sanitaria Fundación Jiménez Díaz, Madrid, Spain

${ }^{3}$ CIBER de Enfermedades Respiratorias (CIBERES)

J Investig Allergol Clin Immunol 2018; Vol. 28(6): 433-434 doi: $10.18176 /$ jiaci.0311

Key words: Drug allergy. Doxylamine. Basophil activation test. Pregnancy. Antihistamines.

Palabras clave: Alergia a medicamentos. Doxilamina. Test de activación de basófilos. Embarazo. Antihistamínicos.

Nausea and vomiting are very common in pregnancy, affecting $75 \%-80 \%$ of pregnant women. The most serious type of nausea and vomiting, known as hyperemesis gravidarum, is much less frequent and affects $0.3 \%-3 \%$ of all pregnant women [1]. Hyperemesis gravidarum can be treated using 3 options [2]: doxylamine $10 \mathrm{mg}+$ pyridoxine $10 \mathrm{mg}$ (Cariban, Inibsa Ginecologia S.A.), dimenhydrinate, and metoclopramide. The development of allergy to the first treatment option (doxylamine + pyridoxine) requires the prescription of secondline drugs with a higher rate of adverse effects in a particularly sensitive group. Because of their rarity, these hypersensitivity reactions may be misdiagnosed. We present the first report of a case of hypersensitivity to doxylamine demonstrated using the basophil activation test (BAT).

A 34-year-old primigravida was referred to our allergy clinic with intractable vomiting that started 4 weeks after becoming pregnant. Since the vomiting did not resolve with dietary measures, her obstetrician prescribed 4 tablets daily of doxylamine succinate $10 \mathrm{mg}+$ pyridoxine hydrochloride $10 \mathrm{mg}$. After less than 60 minutes of taking the first 2 tablets, the patient experienced dizziness, shortness of breath, and generalized pruritus. Consequently, she went to the emergency department, where she was diagnosed with hypotension $(70 / 52 \mathrm{mmHg})$ and urticaria on the trunk and extremities, although oxygen saturation was appropriate. She received intravenous hydrocortisone and dexchlorpheniramine, and her symptoms resolved within 2 hours. When the patient came to our allergy clinic, she was diagnosed with anaphylaxis caused by Cariban. Intraepidermal tests were performed using the prick-byprick technique with oral doxylamine $25 \mathrm{mg}$ (Dormidina sachets, Laboratorios Pensa). No tests were performed with pyridoxine (Benadon, Teofarma), because the drug was not available in our clinic. A positive result was obtained with doxylamine $(8 \times 6 \mathrm{~mm})$ in the patient and a negative result $(2 \times 1 \mathrm{~mm})$ in a nonatopic control. As the results of the skin

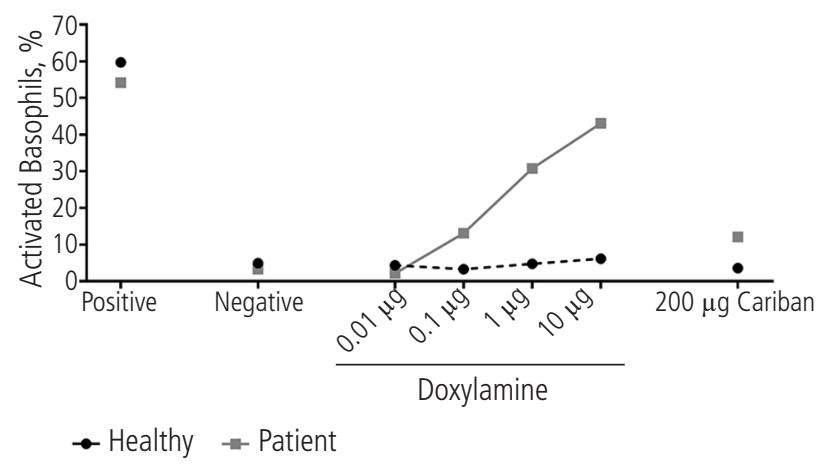

Figure. Basophil activation test with doxylamine and Cariban.

tests were positive and the reaction under study was very serious, we decided not to carry out an oral challenge test to confirm the diagnosis, preferring a BAT instead. The BAT has previously proven useful for confirming the involvement of a drug in cases of anaphylaxis [3-7]. It was performed with the patient's blood sample and blood from a nonatopic healthy control. The population of basophils was defined as CD203c $\mathrm{c}^{+} /$ $\mathrm{SSC}^{\text {low }}$ by flow cytometry. The results are expressed as the percentage of $\mathrm{CD}^{+} 3^{+}$basophils (activated basophils). The BAT result was positive, with $>10 \%$ of the patient's basophils activated after stimulation with the second smallest dose of doxylamine (10 ng). Activation increased in a dose-dependent manner to levels of over $40 \%$, similar to those of the positive control $(10 \mu \mathrm{L})$ with the highest dose of doxylamine $(10 \mu \mathrm{g})$ (Figure). No activation of basophils was observed in the nonallergic control after stimulation with the allergen, yet the control basophils were activated in the patient with the positive stimulation control (Figure). We also tested whether the commercial drug activated basophils from the patient and observed that when we incubated the patient's basophils with $200 \mu \mathrm{g}$ of Cariban, activation was over $10 \%$ in the patient $(12 \%)$, that is, higher than the nonallergic control basophils stimulated with the same amount of Cariban (3.6\%).

Taken together, our results enable us to confirm that the patient in the present case is allergic to doxylamine, both in the pure form and as Cariban.

Diagnosis of drug allergy is difficult, because the underlying mechanisms are not yet clear and the allergenic structures are mostly unknown. Although challenge testing is the gold standard for the diagnosis of drug allergies, there are potential risks of systemic reactions. In the case of the patient we report, the reaction after exposure to doxylamine was a life-threatening reaction. BAT has several advantages over conventional diagnostic tools, namely, safety, specificity, and the possibility of evaluating multiple drugs at the same time. BAT has been validated for the diagnosis of hypersensitivity to ß-lactams, aspirin/nonsteroidal antiinflammatory drugs, contrast media, and fluoroquinolones [8]. To our knowledge, this is the first time BAT has been used for the diagnosis of allergy to doxylamine. In conclusion, we suggest that BAT is a useful diagnostic tool when deciding on the clinical approach to patients with hypersensitivity to medications. 


\section{Funding}

The authors declare that no funding was received for the present study.

\section{Conflicts of Interest}

The authors declare that they have no conflicts of interest.

\section{References}

1. London V, Grube S, Sherer DM, Abulafia O. Hyperemesis Gravidarum: A Review of Recent Literature. Pharmacology. 2017;100(3-4):161-71.

2. Koren G. Safety considerations surrounding use of treatment options for nausea and vomiting in pregnancy. Expert Opin Drug Saf. 2017 Nov;16(11):1227-34.

3. Couto M, López-Salgueiro $R$, Gaspar Â. Anaphylaxis to Etoricoxib. J Investig Allergol Clin Immunol. 2018;28(2):135-6.

4. Arochena L, Zafra MP, Fariña MC, del Pozo V, FernándezNieto M. Acute generalized exanthematic pustulosis due to ibuprofen. Ann Allergy Asthma Immunol. 2013 May; 110(5):386-7.

5. De Weck AL, Sanz ML, Gamboa PM, Aberer W, Blanca M, Correia $S$, et al. A. Nonsteroidal anti-inflammatory drug hypersensitivity syndrome. A multicenter study. I. Clinical findings and in vitro diagnosis. J Investig Allergol Clin Immunol. 2009;19(5):355-69.

6. De Week AL, Sanz ML, Gamboa PM, Aberer W, Sturm G, Bilo $M B$, et al. Diagnosis of immediate-type beta-lactam allergy in vitro by flow-cytometric basophil activation test and sulfidoleukotriene production: a multicenter study. J Investig Allergol Clin Immunol. 2009;19(2):91-109.

7. Lobera T, Audícana MT, Alarcón E, Longo N, Navarro B, Muñoz D. Allergy to quinolones: low cross-reactivity to levofloxacin. J Investig Allergol Clin Immunol. 2010;20(7):607-11.

8. Song WJ, Chang YS. Recent applications of basophil activation tests in the diagnosis of drug hypersensitivity. Asia Pac Allergy. 2013 Oct;3(4):266-80.

Manuscript received July 2, 2018; accepted for publication August 27, 2018.

Manuel Rial Prado

Allergy Department

Hospital Universitario Fundación Jiménez Díaz

Madrid, Spain

E-mail: manuel.rial@quironsalud.es 